\title{
Identifying Motivators and Challenges to BIM Implementation Among Facilities Managers in Johannesburg, South Africa
}

\author{
Chioma Okoro ${ }^{1}$, Innocent Musonda and Andre Kruger
}

1 Finance and Investment Management Department, College of Business and Economics, University of Johannesburg, South Africa, chiomao@uj.ac.za

2 Construction Management and Quantity Surveying Department, School of Civil Engineering and the Built Environment, University of Johannesburg, South Africa, imusonda@uj.ac.za

3 Finance and Investment Management Department, College of Business and Economics, University of Johannesburg, South Africa, akruger@uj.ac.za

\begin{abstract}
The use of technology such as building information modelling (BIM) during the operational and management phase of a building helps to improve facilities and asset performance. However, the slow uptake of building information modelling (BIM) in the facilities and asset management industry diminishes the value derivable from properties and assets in general. The current study examines the motivation to adoption of BIM in the facilities and asset management industry and identifies barriers or challenges to BIM implementation in the sector. A field questionnaire survey was used to collect data among facilities management firms in Johannesburg South Africa. Empirical data from 17 participants were analysed to output frequencies on the challenges of BIM implementation. Findings revealed that competitive advantage, innovativeness, peer-push, as well as organisational image and objectives were motivators for adopting BIM in facilities management. The challenges of BIM implementation were mostly a lack of knowledge (trained personnel) on how to use BIM in facilities management, data management quality, lower data management standards (quality) at the operational stage, inadequate data provision for maintenance and management of facilities. Other issues included limited coordination or cooperation from team members and stakeholders on projects, absence of guidance on best practices to ensure performance optimisation and facilities management support using BIM, and financial commitment and infrastructure involved.
\end{abstract}

(c) 2020 The Authors. Published by Budapest University of Technology and Economics \& Diamond Congress Ltd Peer-review under responsibility of the Scientific Committee of the Creative Construction Conference 2020.

Keywords: assets, BIM, facilities, management, performance

\section{Introduction}

Facilities management has been around for ages. The aim of facilities management is to enhance performance of existing buildings and assets. As real estate development involves a number of participants who enter and depart at different times from design through construction, to occupation and operational stages, loss or distortion of knowledge or information is a concern [1]. One of the ways of ensuring efficient management of information and other processes to enhance the performance of buildings is through the adoption of new technologies such as building information modelling (BIM) [2]. BIM is a comprehensive system, which integrates the various aspects of the life cycle of a project [3]. It is an advanced process by which information about buildings and assets is generated, stored, managed, transferred and shared in an interoperable and reusable way, and thus enhancing performance and improving efficiency of facility 
management functions throughout the life cycle [4], [5]. The use of new technologies in facilities management functions is important given that value is created at the operational stage during the use of an asset [6]. Therefore, ways to ensure that the value in use is sustained warrant consideration.

Value can be improved through different ways in facilities management including the use of new technologies to improve information transfer, design, construction and visualisation of management needs prior to the operational stage. Studies have shown that adopting BIM increases operational efficiency, competitive advantage, performance and cost benefits, improves maintenance management and ultimately, building value [3], [7]. However, it appears that the focus has mostly been on the design and construction stages, in research and in practice [8]. Despite emphasis on the importance of ensuring improved performance of existing buildings and facilities, it is surprising that the uptake of BIM is less emphasized and applied at management and operations stage, as opposed to the design and construction stages. The slow adoption of new technologies in the management of facilities and assets is thus of great concern as it affects operational, strategic and organisational management [9]. The benefit of BIM for maintenance and information management within facilities management organisations has not been explored greatly [8].

Previous studies have focused on motivating factors, for example, the study by [3] highlighted motivators to adopt BIM, and discussed ways to encourage adoption of BIM in the construction industry in Iraq. [2] investigated the advantages of 3D laser scanning technology over the current technologies available for the built environment. [10] identified challenges of BIM implementation in the architecture, engineering and construction industry as organisational factors, lack of knowledge and skilled personnel, high cost of implementation, but without particular focus on the operational stage. [11] conducted a review of BIM implementation challenges. Other studies have been conducted in the United Kingdom [5], in China [12], and in the United States [13]. It appears that there is little evidence of the challenges faced by facility managers in South Africa. Research on BIM adoption and challenges or barriers to implementing BIM in facilities management in South Africa is therefore warranted.

Consequently, for the facilities management sector to enjoy the associated benefits, there is a need to identify what could motivate or drive facilities managers to adopt BIM as a new way of practice, as well as the challenges or barriers that may hinder BIM implementation. The current study therefore identifies the motivators and challenges to BIM implementation in the facilities management sphere using a quantitative approach. A literature review and thematic analysis was conducted, followed by a questionnaire survey on the challenges or barriers to BIM adoption in facilities management practice. A review of related literature on BIM in facilities management is presented hereunder, followed by the methods employed in conducting the study, findings and discussion, as well as the conclusions drawn from the study.

\section{BIM-enabled facilities management - Motivation and challenges}

Facilities management encompasses multiple interdisciplinary functions and integrates people, place, process and technology required to coordinate with organisation strategies and achieve set goals and activities including preventive maintenance and retrofits, space management, energy use monitoring and decision-making [12], [14], [15]. Achieving the goals of an organisation, efficiently, therefore requires effective processes in place. New technologies such as BIM can be used in facilities management functions to cut down operations, boost efficiency, enhance the quality of the facilities and ensure sustainability and overall performance of the organization, which encompasses the aim of facilities management [15]. In the same vein, the goal of BIM is total resource management which aims to reduce waste and costs, increase productivity, improve service delivery, cash flow and profit [16]. A BIM is a 3D digital description of a building, comprising an individual building, its site or GIS objects with attributes that define their detailed description and relationships that specify the nature of the context with other objects [2]. A BIM has robust geometry, comprehensive an extensible object properties, integrated information system (holding all information in one repository), and supports data over facility life cycle from conception to demolition [2]. It therefore contains data that can be assessed and exported for use at a later stage in the life of a project, that is, the maintenance and operational stage and ddecisions can be made more efficiently with visual information made available to all parties, for example in Figure 1. 


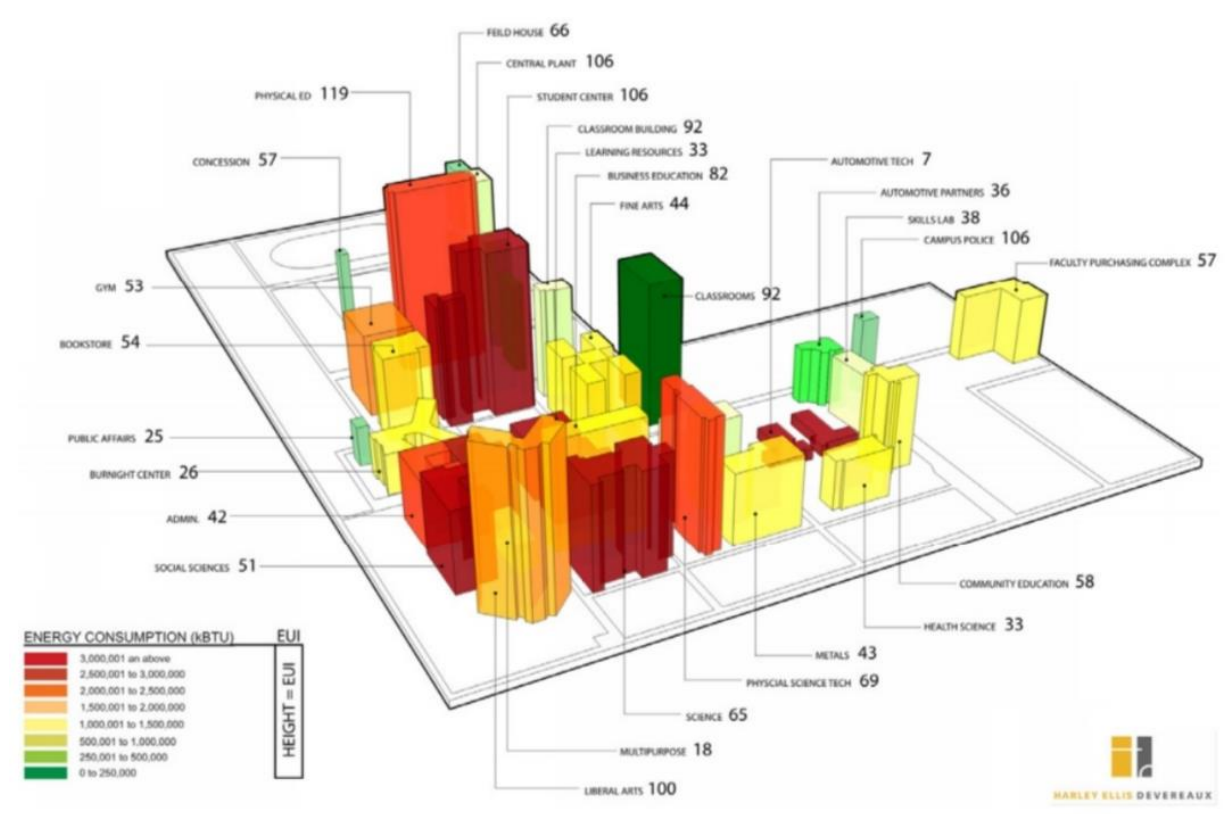

Fig. 1. Prioritising maintenance based on energy-efficiency [14]

As real estate development involves a number of participants who enter and depart at different times from design through construction, to occupation and operational stages, loss or distortion of knowledge or information is a concern [1]. Nonetheless, it does not suffice to have data. Sometimes the information in reality exists, but this fact is not known, or it is not easily accessible or compatible, or coherent, and thus leading to the unnecessary duplication of efforts and resources [2]. Therefore, practitioners might be motivated to reduce or prevent loss of information and other inconvenience that may arise (such as delays). In addition, problems in facilities management as identified by [17], which can occur can be alleviated with the implementation of BIM. Such problems include inadequate technical knowledge and expertise, lack of participation from all relevant departments due to lack of understanding on the importance of providing a comprehensive facilities management in order to achieve set objectives, lack of proper facilities management guidelines and requirements and performance indicators to standardize the practice and implementation of BIM [17]. Good quality and performance in facilities management should be demonstrated to address technical aspects and to achieve clients' satisfaction [12]. Further, operational efficiency, improved building performance, faster and more effective processes, better production quality, controlled whole life costs and environmental data, better integration of planning and implementation processes, and a more effective industry, are motivators for the adoption of BIM technologies in facilities management practice [2], [3], [7], [8].

Notwithstanding its benefits, some challenges associated with the adoption of BIM in FM were identified as either process-related (for example market-readiness, project phase applied, training costs) or technologyrelated [7]. Other studies suggest that the following may hinder the implementation of BIM in facilities management:

- information management standards at the operational stage falling behind those in building design [9];

- limited coordination between the designer and operator in defining the provision of data to support operational management [9], 17];

- market-readiness [7];

- the absence of detailed guidance in how BIM could be best utilised to support ongoing building performance optimisation [9], [17];

- the difficulty in accurate modelling of complex high-performance features, ineffective use of those optimisations and inaccuracy of predictions, which could increase the chances of performance disparity [9]; 
- legal/ contractual and data ownership issues [4], [7];

- personnel inadequacies in terms of training, and skills or competence in the use of BIM application and requirements [4], [17];

- costs of training and provision of required infrastructure (including tools and license) to implement [2], [4], [7]; and

- a lack of real cases where BIM application is demonstrated in a replicable form or context-specific information [4], [7], [8], [9].

Further, interoperability and enhancement of data integration; augmented knowledge management and enriched training and competence development for facility managers can hinder the extent to which BIM is adopted and utilised among facilities managers and practitioners [1]. The current benefit of BIM in operations among Dutch semi-public and public clients was marginal as a result of a lack of alignment between the supply and demand for information as well as the context-dependent role of information [8]. In addition, [4], [11] argue that the lack of methodologies that demonstrate the tangible benefits of BIM in FM as well as determining who owns the data are challenges.

In summary, the tangible and intangible benefits from the use of BIM in facilities management cannot be realised fully if the barriers to BIM implementation in existing buildings are not given consideration. The next section presents the results of survey conducted on the barriers/challenges of BIM implementation among facilities management entities in Johannesburg, South Africa.

\section{Methods}

The study adopted a quantitative approach to determine the challenges or barriers, which facilities managers may face in the adoption of BIM in their operations. A questionnaire, developed from a review of literature, containing ten questions on a 5-point Likert scale, was used. The ethics committee of the researcher's department approved the study prior to self-administration of the questionnaire. The participants, identified through a database of facilities managers in South Africa identified through a Google search, using purposive and convenience sampling techniques, were contacted in person, telephonically and via email. Although effort was made to include more participants in the study, twenty-one respondents participated in the study. The empirical data were analysed using the statistical package for the social sciences (SPSS). The outputs were descriptive statistics (mean and modal scores) regarding the perceived challenges with BIM implementation in facilities management practice. The Cronbach alpha test was used to assess the internal consistency reliability of the measures. The alpha value of 0.951 indicated excellent internal consistency reliability [18]. The following section presents the findings on the challenges of BIM implementation among the sampled facilities management organisations.

\section{Findings and discussion}

\subsection{Demographic characteristics}

The respondents included twelve practitioners from public and four from the private sectors, respectively. One of the participants did not indicate the type of organisation they worked with. Six of the respondents were from government entities, three were from educational institutions, and two were from the healthcare sector and professional facilities management organisations, respectively (Figure 2). One of the respondents was from the IT sector and three were from "other" organisations, comprising state-owned enterprises. They included repairs and maintenance managers, technical advisors, managers, real estate lead, facilities management specialists and senior surveyor, with years of experience mostly between 10 14 years. 


\section{Respondents' specific organisation}

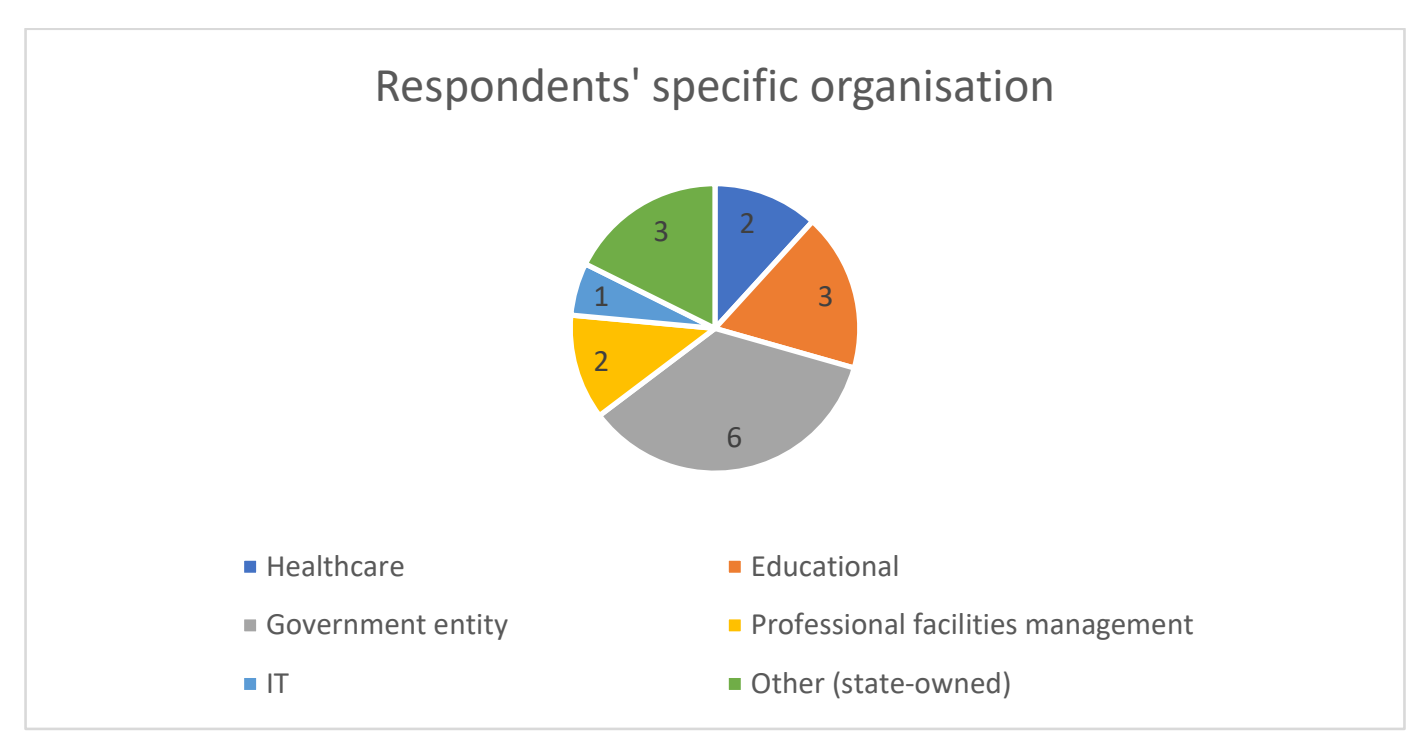

Fig. 2. Respondents' specific organisation type

\subsection{Challenges of BIM implementation}

Respondents were asked their perceptions on the benefits of BIM implementation in facilities management. Table 1 showed that they were mostly in agreement regarding the statements as listed, with the modal scores of 4.0. However, lack of knowledge (trained personnel) on how to use BIM in facilities management had the highest mean score (MS=4.06), followed by lower data management standards (quality) at the operational stage (MS= 3.94). These findings are in line with the views expressed in [9], [10], [15], that the lack of best practice and guidelines on how BIM can be used to support facilities management functions hinder adoption and implementation of BIM. In addition, poor information quality and issues around data exchange and transfer have been highlighted. The quality as well as suitability and accuracy of BIM information and flow is crucial for facilities management decision-making [15]. However, most models created for design and construction phases contain significant quality issues including inaccurate (in terms of spatial association), incomplete, or unnecessary information [15].

In addition, respondents were in agreement that limited cooperation from team members on projects (MS= 3.76), lack of guidelines on how BIM could be used to support building and facilities management (MS= 3.71), $B I M$ infrastructure including license is expensive (MS= 3.71) and poor information transfer from design and construction teams to the facilities management team (MS=3.71). These findings also correspond with results in [9], [11], [15]. The time and cost of hiring trained personnel or training on the use of BIM, as well as acquiring the license and tools for implementation are hindrances to adopting BIM in facilities management practice.

The results also showed that the respondents tended to be neutral with the statements, difficulty in accessing original design data due to technological advancement and development of new BIM software, and difficulty in accessing design data due to network security with the modal scores of 3.0. Although these factors ranked the least, with mean scores of 3.41 and 3.35, respectively, they were identified as barriers to BIM implementation in facilities management practice [11]. However, these problems were associated with the 2D plane models which designers used in the past and it was difficult for some professionals to understand [14]. Interoperability and access can be achieved with a 3D and 4D model and through the use of specific requirements such as Revit plugins which enables easy updating of information and reports on facilities management status [14], [19]. 
Table 1. Challenges of BIM implementation in facilities management

\begin{tabular}{|c|c|c|c|c|}
\hline S/No. & Measures & Mean & Mode & Rank \\
\hline 1 & $\begin{array}{l}\text { Lack of knowledge (trained personnel) on how to use BIM in facilities } \\
\text { management }\end{array}$ & 4.06 & 4 & 1 \\
\hline 2 & Lower data management standards (quality) at the operational stage & 3.94 & 4 & 2 \\
\hline 3 & Inadequate data provision for maintenance and management of facilities & 3.88 & 4 & 3 \\
\hline 4 & Limited cooperation from team members on projects & 3.76 & 4 & 4 \\
\hline 5 & $\begin{array}{l}\text { Lack of guidelines on how BIM could be used to support building and facilities } \\
\text { management }\end{array}$ & 3.71 & 4 & 5 \\
\hline 6 & BIM infrastructure including license is expensive & 3.71 & 4 & 5 \\
\hline 7 & $\begin{array}{l}\text { Poor information transfer from design and construction teams to the facilities } \\
\text { management team }\end{array}$ & 3.71 & 4 & 5 \\
\hline 8 & Lack of real cases where BIM application is clearly demonstrated & 3.47 & 4 & 8 \\
\hline 9 & $\begin{array}{l}\text { Difficulty in accessing original design data due to technological advancement } \\
\text { and development of new BIM software }\end{array}$ & 3.41 & 3 & 9 \\
\hline 10 & Difficulty in accessing design data due to network security & 3.35 & 3 & 10 \\
\hline
\end{tabular}

\section{Conclusion}

The study set out to investigate the motivators and challenges of BIM implementation among facilities management firms in Johannesburg, South Africa. The findings from literature review showed that the motivators for BIM implementation in facilities management include competitive advantage, innovativeness, and organisational image. Findings from the field survey revealed that the challenges of adopting and implementing BIM, among the sampled organisations, include a lack of knowledge (trained personnel) on how to use BIM in facilities management, data management quality, lower data management standards (quality) at the operational stage, inadequate data provision for maintenance and management of facilities. The findings of the study are envisaged to assist facilities management organisations in identifying ways to overcome the challenges identified and ultimately achieve their objectives efficiently and effectively sin e adopting new technologies in this era of the fourth industrial revolution is pertinent. The sample size limitation of the study warrants mention. Data could be collected from a larger sample to explore the challenges of BIM implementation in facilities management entities.

\section{Acknowledgement}

The authors thank Ms Kristen Cindy Scheepers, for assisting with making contact with the respondents during the data collection stage.

\section{References}

[1] Araszkiewicz, K. (2017). Digital technologies in Facility Management - the state of practice and research challenges. Procedia Engineering 196: 1034 - 1042 https://doi.org/10.1016/j.proeng.2017.08.059

[2] Arayici, Y. and Tah, J. (2008). Towards Building Information Modelling for Existing Structures, Structural Survey, 2008 https://doi.org/10.1108/02630800810887108

[3] Xu, X., Ma, L. and Ding, L. (2014). A Framework for BIM-enabled Life-cycle Information Management of Construction Project. International Journal of Advanced Robotic Systems, 11 (126): 1-13. https://doi.org/10.5772/58445

[4] Kassem, M., Kelly, G., Dawood, N. Serginson, M. and Lockley, S. (2015). BIM in facilities management applications: A case study of a large university complex. Built Environment Project and Asset Management, 5(3): 261-277. https://doi.org/10.1108/BEPAM-022014-0011

[5] Kiviniemi, A. and Codinhoto, R. (2013) Challenges in the implementation of BIM for FM case Manchester town hall complex. https://core.ac.uk/download/pdf/80772321.pdf

[6] Isa, N. M., Kamaruzzaman, S. N., Mohamed, O. Berawi, M. A. (2017). Review of facilities management functions in value management practices. International Journal of Technology 5: 830-840 https://doi.org/10.14716/ijtech.v8i5.865

[7] Edirisinghe, R., London, K. A., Kalutara, P. and Aranda-Mena, G. (2017). Building information modelling for facility management: are we there yet? Engineering, Construction and Architectural Management, Vol. 24 Issue: 6, pp.1119-1154. https://doi.org/10.1108/ECAM-06-2016-0139

[8] Bosch, A., Volker, L. and Koutamanis, A. (2015). BIM in the operations stage: Bottlenecks and implications for owners. Built Environment Project and Asset Management 5(3):331-343 https://doi.org/10.1108/BEPAM-03-2014-0017

[9] Gerrish, T., Ruikar, K., Cook, M., Johnson, M., Phillip, M. and Lowry, C. (2017). BIM application to building energy performance visualisation and management: Challenges and potential. Energy and Buildings 144: 218-228 https://doi.org/10.1016/j.enbuild.2017.03.032

[10] Tivendale, L. and Liu, C. (2015). Critical Barriers to BIM Implementation in the AEC Industry. International Journal of Marketing Studies, 7(6): 162-171 https://doi.org/10.5539/ijms.v7n6p162

[11] Li, P., Zheng, S., Si, H. And Xu, K. (2019). Critical challenges for BIM Adoption in Small and Medium-Sized Enterprises: Evidence from China. Advances in Civil Engineering, 2019: 1-15. https://doi.org/10.1155/2019/9482350 
[12] Chong, H., Wang, J., Shou, W., Wang, X. and Guo, J. (2014). Improving Quality and Performance of Facility Management Using Building Information Modelling, Cooperative Design, Visualization, and Engineering, 44-5. https://doi.org/10.1007/978-3-319-108315 _6

[13] Becerik-Gerber, B., Jazizadeh, F., Li, N. and Calis, G. (2012). Application areas and data requirements for BIM-enabled facilities management. Journal of Construction Engineering and Management, 138(3): 431-442. https://doi.org/10.1061/(ASCE)CO.19437862.0000433

[14] Su, Y. C., Lee, Y. C. and Lin, Y. C. (2010). Enhancing maintenance management using building information modelling in facilities management. CIB DC23734. Pp. 752-757. https://doi.org/10.22260/ISARC2011/0140

[15] Naghshbandi, S. N. (2016) BIM for Facility Management: Challenges and Research Gaps Civil Engineering Journal, 2(12), 679-684. https://doi.org/10.28991/cej-2016-00000067

[16] Aziz, N. D., Nawawi, A. H. and Ariff, N. R. M. (2016). Building Information Modelling (BIM) in Facilities Management: Opportunities to be considered by Facility Managers. Procedia - Social and Behavioral Sciences 234: $353-362$ https://doi.org/10.1016/j.sbspro.2016.10.252

[17] Mustapa, H. S. A., Adnan, H., and Jusoff, K. (2008). Facility Management Challenges and Opportunities in the Malaysian Property Sector, Journal of Sustainable Development, 1 (2): $79-85$ https://doi.org/10.5539/jsd.v1n2p79

[18] Pallant J. (2013) "SPSS Survival Manual: A Step by Step Guide to Data Analysis using IBM SPSS". $5^{\text {th }}$ Edition. Allen and Unwin. Australia. 2013. https://doi.org/10.1111/1753-6405.12166

[19] Kensek, A. (2015). BIM guidelines inform facilities management databases: A case study over time. Buildings, 5: 899-916. https://doi.org/10.3390/buildings5030899 